\title{
Mucoepidermoid Carcinoma of the Vulva: A Distinct Pathological and Clinical Entity
}

\begin{abstract}
Unlike their major salivary gland counterparts, primary mucoepidermoid carcinoma of the vulva is extremely rare tumor. Here, we describe an unusual case of MEC arising from vulva and a short review of literature. This report describes an interesting and unusual case of mucoepidermoid carcinoma of vulva. A 42-year female presented with approx. $3.5 \times 3.0 \mathrm{~cm}$ size painless polypoidal growth on right labia majora. CT scan abdomen \& pelvis showed 30 x $27 \mathrm{~cm}$ size well defined lobulated polypoidal lesion is noted in right side of labia majora. Wide local excision had done with margin. Histological evaluation revealed a typical MEC with negative margin. Our tumor board has decided to keep on close follow-up because of the aggressive behaviour of such type of tumour. Follow-up at 6 months has revealed no evidence of recurrence. This is, to our knowledge, the first report of MEC arising from vulva in India. We report a very rare case of primary mucoepidermoid carcinoma of the vulva and this is the first case reported in India. Treatment strategy for MEC vulva yet to decide and patients should be closely followed-up for life to rule out late recurrence.
\end{abstract}

Keywords: Carcinoma vulva, mucoepidermoid carcinoma, Mucoepidermoid Carcinoma of the Vulva

\section{Introduction}

Mucoepidermoid carcinoma (MEC) is first described by Stewart et al. as a malignant epithelial tumor of the salivary gland in $1945 .^{[1]}$ MEC is very common in the salivary gland but extremely rare in the vulva. We experienced a case of primary MEC of the vulva and reported the case as the first report in India.

\section{Case Report}

A 42-year-old female from district Vaishali (Bihar, India) presented to Mahavir Cancer Sansthan on September 18, 2017, with a complaint of gradually developing lump on the right labia majora for the past 2 months. On examination, there is a painless, polypoidal growth, firm to hard in consistency, and of size approximately $3.5 \mathrm{~cm} \times 3.0 \mathrm{~cm}$ present on the right labia majora. There was no history of any major surgery or any addiction. Menstrual history is normal. Computed tomography (CT) scan of the abdomen and pelvis was done on September 19, 2017, which showed $30 \mathrm{~cm} \times 27 \mathrm{~cm}$ size well-defined lobulated polypoidal lesion noted on the right side of the labia majora [Figures 1 and 2].

This is an open access journal, and articles are distributed under the terms of the Creative Commons Attribution-NonCommercial-ShareAlike 4.0 License, which allows others to remix, tweak, and build upon the work non-commercially, as long as appropriate credit is given and the new creations are licensed under the identical terms.

For reprints contact: reprints@medknow.com
Wide excision with margin was done on September 26, 2017. Histopathological report showed high-grade MEC. Tumor is $0.5 \mathrm{~cm}$ away from skin resection margin and $0.5 \mathrm{~cm}$ away from soft-tissue resection margin [Figures 3 and 4].

Tumor board on October 10, 2017, has decided to keep the patient on close follow-up because of the diverse biological behavior of such type of tumor. Follow-up at 6 months has revealed no evidence of recurrence or distant metastasis, and the patient is doing well with performance status 0 .

\section{Discussion}

MEC is the most common malignant major and minor salivary gland tumor comprising about $10 \%$ of all salivary gland neoplasms and approximately $35 \%$ of malignant salivary gland neoplasms. ${ }^{[2]}$ In 1945, Stewart et al.$^{[1]}$ introduced the term mucoepidermoid to define a distinct salivary gland tumor characterized by a mixed pattern of the following two main cells types: epidermoid and mucus-producing cells. However, a third cell type, the intermediate cell, which is not mucous or fully epidermoid, is often present. Intermediate cells are thought to be

How to cite this article: Sinha SN, Choudhary BK, Kumar S, Singh M. Mucoepidermoid carcinoma of the vulva: A distinct pathological and clinical entity. Indian J Med Paediatr Oncol 2019;40:588-90.

\section{Satyendra Narayan \\ Sinha ${ }^{1}$, Brajesh Kumar Choudhary ${ }^{1}$, Sanjay Kumar ${ }^{2}$, Manisha Singh ${ }^{1}$}

Departments of ${ }^{1}$ Medical Oncology and ${ }^{2}$ Pathology, Mahavir Cancer Sansthan, Patna, Bihar, India

Submitted: $13-A p r-2018$ Accepted in Revised Form: 21-Jun-2018

Published: 17-Feb-2020

Address for correspondence: Dr. Satyendra Narayan Sinha, Department of Medical Oncology, Mahavir Cancer Sansthan, Phulwarisharif, Patna, Bihar, India.

E-mail: drsatyendra4u@gmail. com

Access this article online

Website: www.ijmpo.org

DOI: 10.4103/ijmpo.ijmpo_85_18 Quick Response Code:

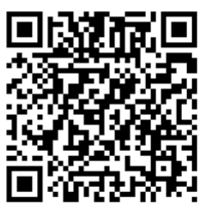




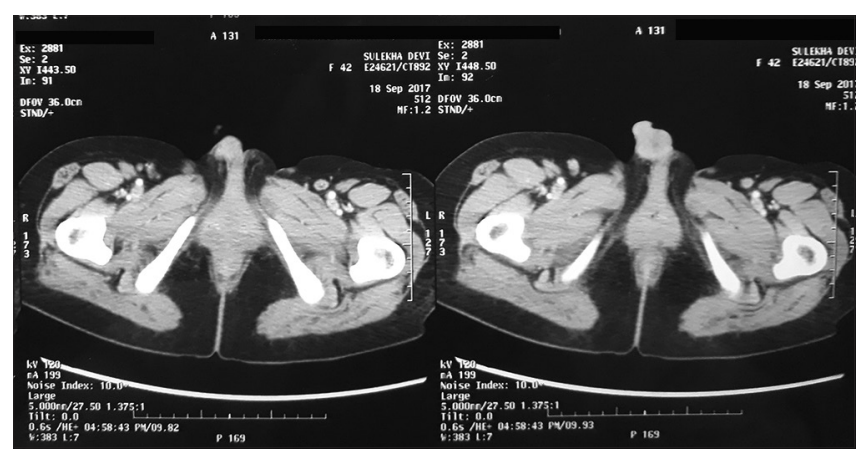

Figure 1: Axial section of computed tomography whole abdomen showing well-defined lobulated polypoidal lesion is noted on the right side of the labia majora

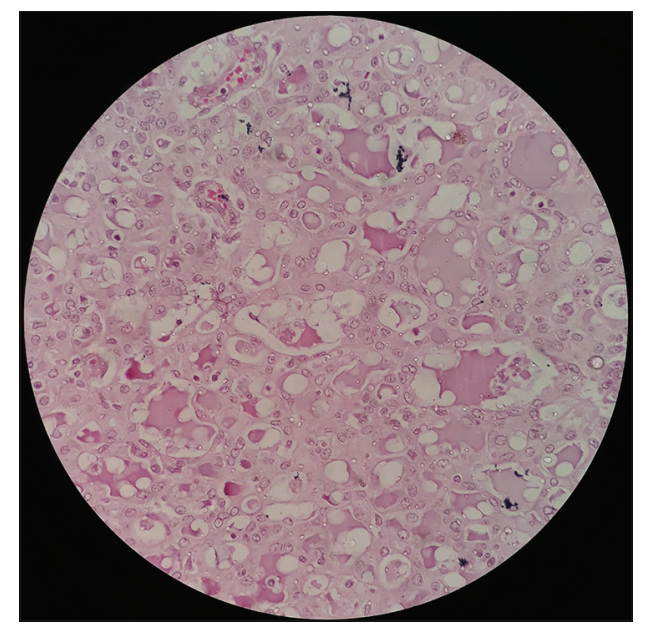

Figure 3: Section showing variable-sized, mucin-filled cystic structure and mucous cells

capable of differentiating into mucous or epidermoid cells. As a result of this cellular heterogeneity, the histologic composition, biological behavior, and clinical course of MEC vary.

Among the major salivary glands, MEC occurs most frequently in the parotid gland. MEC of the vulva is extremely rare. There is only a single case report of MEC of the vulva in Japanese language. ${ }^{[3]}$ In English literature, we could not find even a single report of MEC of the vulva. Our patient presented with lobulated lump on the right vulva, and histopathological report of wide excision revealed that tumor was composed of squamoid, intermediate, and mucin-secreting cells that together formed a variety of patterns with necrotic background. There are variable sized, mucin-filled cystic structures and mucous cells. Mucin-secreting cells showed clear vacuolated cytoplasm forming solid-sheet patterns. The solid areas are formed by squamoid (epidermoid) cells with spindle appearance which lacks intercellular bridging, pale to eosinophilic cytoplasm, and distinct cell borders. It contains more solid area as compared to cystic spaces which are suggestive of high-grade tumor. Both resecting margins were tumor free. There is no standard treatment in

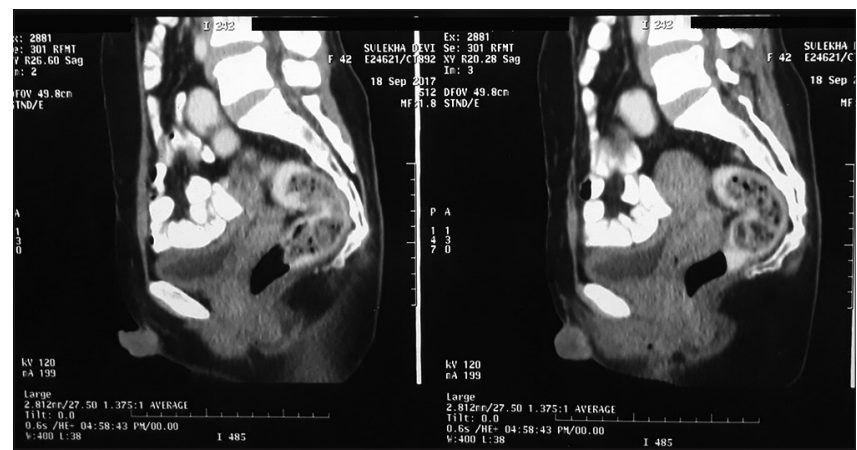

Figure 2: Sagittal section of computed tomography whole abdomen showing well-defined lobulated polypoidal lesion is noted on the right side of the labia majora

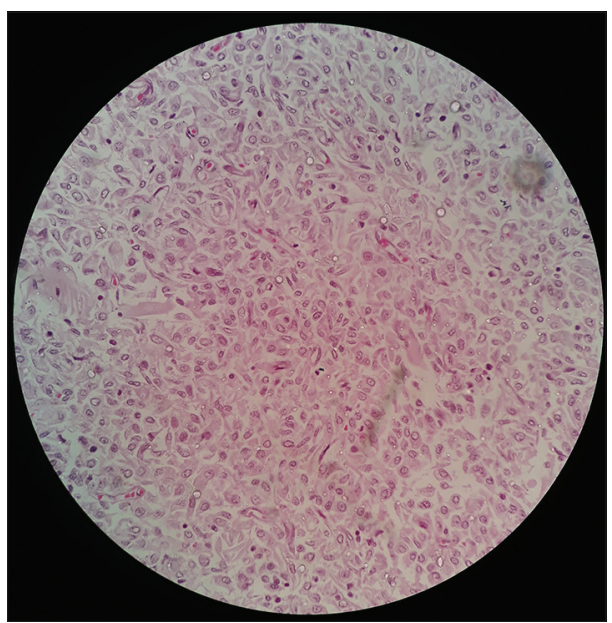

Figure 4: Section showing squamoid cells with spindle appearance which lacks intercellular bridging

vulva MEC because of the rarity entity and limited date. Here, we keep the patient on close follow-up and 6 months has already elapsed, there is no evidence of recurrence or distant metastasis, and the patient is doing well with performance status 0 .

\section{Conclusion}

We report a very rare case of primary MEC of the vulva, and this is the first case reported in India. MEC is a unique carcinoma as it demonstrates a broad spectrum of aggressiveness from indolent tumors that are cured by surgery alone to aggressive neoplasms that are prone to local invasion, recurrence, and metastasis. Treatment strategy for MEC vulva yet to decide and patients should be closely followed up for life to rule out late recurrence.

\section{Declaration of patient consent}

The authors certify that they have obtained all appropriate patient consent forms. In the form the patient(s) has/have given his/her/their consent for his/her/their images and other clinical information to be reported in the journal. The patients understand that their names and initials will not 
be published and due efforts will be made to conceal their identity, but anonymity cannot be guaranteed.

\section{Acknowledgment}

We would like to express our special thanks and gratitude to my teacher cum HOD Dr. Manisha Singh who regularly appreciates us for study and research work.

\section{Financial support and sponsorship}

Nil.

\section{Conflicts of interest}

There are no conflicts of interest.

\section{References}

1. Stewart FW, Foote FW, Becker WF. Muco-epidermoid tumors of salivary glands. Ann Surg 1945;122:820-44.

2. Speight PM, Barrett AW. Salivary gland tumours. Oral Dis 2002;8:229-40.

3. Yamabe T, Matsumoto M, Yasunaga M. Case of mucoepidermoid tumor of the vulva. Gan No Rinsho 1971;17:838-41. 